\title{
Out of Hours Insight
}

by less than $1 \mathrm{~kg}$ in weight, suggesting a genetic element. But genes don't change in a generation, so what's going on?

Tim Spector, a professor of genetic epidemiology at King's College London, studies twins and the microbiology of bowel contents. This book presents his explanation of why people gain weight, fail to lose weight, and why allergy seems to be everywhere. The book is written for an intelligent lay audience, in a conversational style, well peppered with case histories and reports from research papers. Inadequate or maladapted bowel flora contribute to both obesity and allergies. Spector says the problems begin in utero. Avoiding peanuts and unpasteurised cheeses during pregnancy limits the diversity of a mother's own bowel flora and deprives the fetus of polyphenols (which act as antioxidants, lower lipid levels, and control genes moderating the immune system). A baby born by caesarean section may take over 3 months to develop normal bowel flora and antibiotics given to a mother limit the flora in breast milk. Antibiotics and gastroenteritis purge the gut, impairing digestion, absorption, and sometimes causing inflammation.

After gut purging, what you eat determines how swiftly your gut flora recover. Sugary foods, processed foods, and artificial sweeteners (as bad as sugar) impair the restoration of a healthy microbiome and raise blood sugar and insulin levels.

Spector offers support for the hygiene hypothesis. He recommends that a swab from mum's perineum should be swept over baby's face after a caesarean birth. He advocates playing in the dirt, having pets, perfunctory washing of food, following a Mediterranean diet, with garlic and olive oil (polyphenols), a little meat, plenty of fibre, yoghurt with probiotics, and lots of variety. He gives 'best before' dates short shrift, both for food and drugs. You might use some of the anecdotes in consultations, recommend the book to some patients, enjoy it yourself, and Spector even offers readers an opportunity to have their bowel flora tested.

\section{Stuart Handysides,}

Retired GP, Associate Editor, ProMED-mail. http://www.promedmail.org/

\section{E-mail: stuart_handysidesRahotmail.com}

DOI: 10.3399/bjgp16X685981

\section{The Novel Cure}

Ella Berthoud and Susan Elderkin

Canongate Books, 2015, PB, 464pp, E9.99, 978-0857864215

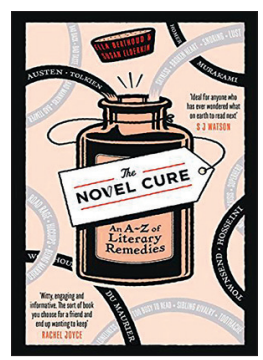

\section{BOOKS AS THERAPY}

This is a book of bibliotherapy: reading matter for anyone wishing to cure themselves of any ailment using cures from literature a list of remedies for conditions ranging from abandonment to zestlessness, and everything in between. Not a novel that you want to sit and read in long sessions, but a book to dip into whenever you feel the need of some help from heroes and heroines of literature.

The illnesses are arranged in alphabetical order and each illness has a book (or a few) that can help with a cure. Each cure may take the form of reading how the protagonist went through a similar problem (/ am Legend by Richard Matheson for coping without family), or help put you off creating a future problem (Atonement by lan McEwan for lyingl. Sometimes it just helps you endure others (suggesting dealing with people who put you under pressure to have children by giving them a copy of We Need to Talk About Kevin by Lionel Shriver: enough to put anyone off reproducing!). This is a book for literary enthusiasts and its humorous and informative guides to different cures make a great source for choosing your next book to read - my reading list has now grown. The book even has advice for being a compulsive book buyer yet not having enough time to read. The recommendations are intriguing, presented with plenty of wit, and I wouldn't hesitate to prescribe this book to bibliophiles wondering what to read next, or to anyone with a love of literature.

\section{Sarah Louise Alderson,}

Clinical Lecturer in Primary Care, Academic Unit of Primary Care, University of Leeds, Leeds.

E-mail: s.l.aldersonAleeds.ac.uk

DOI: 10.3399/bjgp16X685993

\section{A LIGHT BULB MOMENT}

Many years ago, when I was a GP trainer, I went on a visit to an older lady. She was recently bereaved, arthritic, not far from the end of life herself. In those days we did more chronic visits, so that the content of the visit was as much personal as medical. With me I had my current registrar. She was bright, enthusiastic, knowledgeable. As we left, the lady asked me to change a light bulb in the kitchen; her hands were not up to it. I changed the light bulb; it was the work of moments.

As we got back into the car I saw a look of thunder on my registrar's face. She had not trained for 7 years in order to change light bulbs, she told me. If she'd wanted to change light bulbs she could have trained as an electrician, or even - yes, she would come out with it - as a nurse or an occupational therapist. I kept my peace; turned to other matters. Middle-aged now, probably a mother, still, I hope, a GP, these days she probably changes light bulbs for patients without even noticing that she's doing it. But what I could have said then, what I bit back because it would not have helped at that moment, was the following:

You trained for 7 years to acquire more; to acquire more skills, to acquire the status and respect due to a doctor. You did not train for 7 years to become less; you did not train for 7 years to become less human.'

\section{Gervase Vernon,}

GP, John Tasker House Surgery, Dunmow, Essex.

\section{E-mail: Gervaseßjth.demon.co.uk}

DOI: 10.3399/bjgp16X686005 